\title{
EN RECUERdo de EUgenio Bulygin
}

Hace unos meses recibimos la triste noticia del fallecimiento de Eugenio Bulygin (1931-2021). Entre muchas otras cosas, el profesor Bulygin es parte fundamental de la historia de esta revista. No solo por su vínculo con la Universidad Nacional del Sur, sino también por su estrecha colaboración $\mathrm{y}$ amistad con quienes fueron sus fundadores y directores. A modo de homenaje dedicaremos este espacio de la revista para recordarlo, en las palabras de quienes lo conocieron. 



\section{UNAS PALABRAS EN RECUERDO DE EUgENio Bulygin}

Me han pedido que escriba unas líneas en recuerdo de Eugenio Bulygin. Permítaseme ubicarlo en un cierto período histórico. No cabe duda de que la década que transcurre entre 1956 y el golpe de Estado de junio de 1966 se puede describir como un período de oro de la universidad argentina y, especialmente, de la Universidad de Buenos Aires. En todas las disciplinas, en todas las áreas científicas, se produjeron cambios cualitativos que contribuyeron a alcanzar niveles de excelencia comparables a las mejores universidades del mundo. Por supuesto, ello vale también para la Facultad de Derecho de la UBA. Como consecuencia del azar, comencé a cursar en ese espacio la carrera de Derecho en 1963 y pude, entonces, como estudiante, beneficiarme de las clases de profesores de máxima jerarquía académica y puedo dar testimonio de semejantes cambios. Uno que me parece especialmente trascendente fue la notoria modificación que se estaba produciendo en las formas y teorías destinadas a comprender el derecho desde el punto de vista de la filosofía.

En el Instituto de Filosofía del Derecho, durante esos años, y bajo la dirección del mítico profesor Ambrosio Gioja, un grupo de jóvenes intelectuales comenzó a trabajar - y a enseñar- los problemas jusfilosóficos mediante las herramientas de la contemporánea filosofía analítica, en todas sus variantes, hasta entonces ausente en las facultades de derecho de este país. Eugenio Bulygin era un destacado miembro de ese grupo, un genuino agente - junto con sus colegas - de lo que puede calificarse, sin duda alguna, como un cambio cultural de extraordinaria importancia. Por supuesto, ello no debe entenderse como una imposible ruptura con la mejor la tradición en el ámbito de la teoría del derecho, sino como la puesta a punto de nuevos puntos de vista sobre antiguos problemas, incluyendo la posibilidad de mostrar que son pseudoproblemas. Como muestra de semejante cambio, en los cursos de grado se enseñaba la nueva versión de la Teoría Pura del Derecho de Hans Kelsen, la de 1960, en la traducción de 
Discusiones 27

Roberto Vernengo, a la par de la presentación en castellano - por Genaro Carrió- de El Concepto del Derecho, el por entonces reciente y fundamental libro de Herbert L. A. Hart de 1961, el que es — como se sabe- un ingrediente básico de cualquier formación jurídica que se precie. Es verdad que actualmente, es difícil apreciar la importancia y significado de esa genuina transformación cultural, toda vez que las estrategias conceptuales de esta manera de entender la labor filosófica constituyen actualmente un componente habitual de la mejor bibliografía especializada.

Como un verdadero paradigma de ese cambio, Eugenio Bulygin y Carlos Alchourrón publican en 1971, en Nueva York y en Viena, el notable libro Normative Systems, el que pocos años después aparece en Buenos Aires y es posteriormente traducido a otros idiomas. No se puede dejar de reconocer la calidad e importancia de esta obra, como se evidencia en las notas bibliográficas que dan cuenta de ello, en las revistas más relevantes de la comunidad jusfilósofica. Mediante la utilización, básicamente, de ideas de Carnap y del aparato de lógica deóntica de Von Wright este trabajo presenta una precisa reconstrucción conceptual de la idea de "sistema normativo", y de cuestiones asociadas a la estructura formal de sistemas normativos no interpretados, cualquiera sea su origen o naturaleza y cualquiera sea su contenido sustantivo, ya sean sistemas morales, de derecho natural, o de algún derecho positivo. No es en modo alguno, la presentación o defensa - como algunos erróneamente así lo han interpretado- de una teoría, positivista o no positivista sobre el derecho. No obstante ese carácter general, numerosos conceptos de interés jurídico se esclarecen mediante ese análisis, tales como el de "caso" o el de "laguna normativa", a la vez que se discuten, tal vez, a mi criterio, de manera definitiva, interrogantes típicos, como lo es, por ejemplo, el de la existencia, necesaria o no, de normas de clausura en el derecho.

Se puede asumir a Normative Systems como un umbral a partir del cual seguir los pasos del impresionante material teórico que Eugenio Buygin, en forma individual o en conjunto con Carlos Alchourrón, ha producido a lo largo de su extensa carrera. Con indudable talento, ha intervenido en todos los problemas más importantes de la agenda contempórea de discusiones en el espacio de la filosofía del derecho, defendiendo sus ideas en memorables polémicas con otros autores relevantes. Así, cuestiones como la de la existencia de normas, la de la objetividad del derecho, la naturaleza del 
lenguaje normativo, la distinción entre puntos de vista interno y externo, entre otras, abordadas en libros, artículos, conferencias o seminarios conforman ese material de cuya revisión nadie, seriamente, interesado puede prescindir.

A lo largo de toda su obra, hay al menos algunas tesis filosóficas acerca del derecho que Bulygin estuvo, en todo caso, dispuesto a defender. En primer lugar, el positivismo jurídico teórico como única manera racional de enfrentar esas cuestiones. En segundo lugar, el esencial papel de la lógica como herramienta de precisión. Como consecuencia de ello, la distinción entre "norma" y "proposición normativa" de uso imprescindible en cualquier análisis. En tercer lugar, la separación tajante entre teoría y práctica, sin cuya admisión, solo se puede incurrir en confusiones Tal vez, habría que incluir también su escepticismo en metaética.

Está fuera de discusión la calidad de su producción intelectual pero, más importante, es la calidad de la persona que fue Eugenio. Fue generoso, de manera incondicional, con los más jóvenes al apoyarlos sin reservas en sus carreras, o al discutir sus propuestas con la mente abierta. Fue un excelente amigo, dispuesto a colaborar en cualquier empresa académica que estimaba valiosa, amistad que acompañaba siempre con su buen humor y su franca sonrisa. Amaba a su familia, como hijo, esposo, padre y abuelo. Disfrutaba de su casa en Santa Catalina, de una cabalgata, de una visita a alguna iglesia románica o de una buena partida de ajedrez.

Eugenio Bulygin murió en Buenos Aires, en mayo de 2021, cuando restaban pocos meses para alcanzar sus noventa años. Es una gran pena. Pero el legado de su talento constituye una de las formas en las que va a permanecer en nuestra memoria. Sin duda, será así.

Ricardo Caracciolo (Universidad Nacional de Córdoba, Argentina) 